\title{
The Negative Core Beliefs Inventory (NCBI): Development and Psychometric Properties
}

\author{
Flavio Osmo, MSc \\ Victor Duran, MSc Candidate \\ Universidade Federal da Bahia, Salvador, Brazil \\ Amy Wenzel, PhD \\ University of Pennsylvania, Philadelphia, United States \\ Irismar de Oliveira, $\mathrm{PhD}$ \\ Sara Nepomuceno, BSc Candidate \\ Maryana Madeira, BSc Candidate \\ Universidade Federal da Bahia, Salvador, Brazil \\ Igor Menezes, $\mathrm{PhD}$ \\ Universidade Federal da Bahia, Salvador, Brazil \\ Univeristy of Cambridge, Cambridge, United Kingdom
}

\begin{abstract}
Although the core belief construct is central in A. T. Beck's cognitive theory, little empirical research has been conducted to date to establish its psychometric properties as well as the way it explains manifestations of psychopathology. The aims of this study were to develop and provide the first evidence of validity and reliability of a new measure of core beliefs that quantifies negative core beliefs about the self (nCB-S) and negative core beliefs about others (nCB-O). Results indicated that this measure has adequate internal consistency and test-retest reliability. Factor analyses confirmed that nCB-S and nCB-O fall on separate dimensions, and they provided preliminary evidence that nCB-S can be separated further into (a) helplessness/ inferiority, (b) helplessness/vulnerability, (c) unlovability, and (d) worthlessness. Consistent with expectations, the scores on the $\mathrm{nCB}-\mathrm{S}$ and $\mathrm{nCB}-\mathrm{O}$ scales correlated positively with reports of negative experiences in childhood, attachment styles, anxiety, and depression. These preliminary results suggest that core beliefs can be measured in a reliable and valid manner and that the can be used in studies designed to validate aspects of A. T. Beck's cognitive theory.
\end{abstract}

Keywords: core beliefs; schemas; cognitive therapy; anxiety; depressionattachment styles 
A aron T. Beck's cognitive theory is arguably one of the most sophisticated and well-validated approaches to understanding the etiology and maintenance of emotional distress, such as depression and anxiety. According to A. T. Beck's theory, the meaning that a person makes from situations in his or her life plays a large role in understanding the emotional reactions that he or she has to them (Beck, 1964; Beck, Rush, Shaw, \& Emery, 1979; Beck, 2011). Thus, cognition is the cornerstone of understanding emotional distress, and it follows from this model that modifying unhelpful cognition would be associated with reductions in emotional distress (Dobson \& Dozois, 2010).

Several layers of cognition were proposed in A. T. Beck's model. At the most basic level, people experience situation-specific automatic thoughts when they experience emotional reactions to particular circumstances that they face in their lives. However, A. T. Beck also proposed that people's underlying beliefs explain the specific types of automatic thoughts that are experienced in under these circumstances. At the most fundamental level, people are characterized by core beliefs, or central beliefs that they hold about themselves (e.g., "I am worthless") or others (e.g., "Others will hurt me"). According to cognitive theory, negative core beliefs are activated in times of stress and make people vulnerable to experience emotional distress.

Much empirical and clinical attention has been devoted to characterizing and working with cognition at the automatic thought level (Beck, 2011; Hollon \& Kendall, 1980). In contrast, much less empirical and clinical attention has been dedicated to characterizing and working with underlying beliefs. One reason why this is problematic is because experts have suggested that the most enduring changes from cognitive behavioral therapy (CBT) arise from changes, specifically, in negative core beliefs (Beck, 2011; Wenzel, 2012). As such, they propose that shifting core beliefs from those that are primarily negative (e.g. "I'm not good enough") to core beliefs that are balanced and even positive (e.g., "I'm just as good as everyone else") should be associated with lower rates of relapse and recurrence of emotional distress. If this is the case, then it behooves researchers to develop well-validated approaches for measuring core beliefs in order to provide empirical support for the construct, itself, as well as to measure the degree to which they shift throughout the course of CBT.

\section{Core Beliefs: Categories and Relationships Core Beliefs: CATEgories AND RELATIONSHIPS WWwWith ITH ANXIETY AND DEPRESSIONANXIETY AND DEPRESSION}

Core beliefs, defined as fundamental, absolute, and lasting comprehensions that a person develops about him or herself, others, and the world, are constructed from the effort of extracting meaning from significant childhood or formative experiences (Beck, 2011).

To the extent that core beliefs are internalized, they are grouped into categories and form relatively stable cognitive systems (schemas), which serve as the basis for processing and interpreting new information (Beck, 1964; Beck, Freeman, \& Davis, 2015; Clark \& Beck, 1999).

Beck (2005) identified the existence of three categories of negative core beliefs about the self: helplessness, unlovability, and worthlessness. The helplessness category includes several beliefs associated with personal incompetence, vulnerability, and inferiority. The unlovability category's main theme is the belief or fear that one is incapable of obtaining the desired intimacy and attention. The worthlessness category is defined as the presence of negative moral self-attributions in which one believes oneself to be insignificant, a burden to others, and worthless.

Because individuals with a negative representation of themselves are excessively concerned with avoiding rejection (Pietromonaco \& Feldman Barrett, 2000), they seek excessive validation 
from others (Dykman, 1998; Flett, Besser, \& Hewitt, 2014). Any sign of negative evaluation by others can induce feelings of anxiety in such individuals. Another relationship between negative central beliefs and anxiety is proposed by Clark \& Beck (2011). These authors suggest that people who perceive themselves as vulnerable tend to be anxious because they underestimate their personal abilities and exaggerate the probability and severity of threats.

Studies also show that people with negative representations about themselves might present with symptoms of depression after the occurrence of a negative event that can be associated with perceptions of incompetence and worthlessness (Dykman, 1998; Flett, Besser, \& Hewitt, 2014; Morley \& Moran, 2011; Rusk \& Rothbaum, 2010). Beck and Alford (2011) explained that those individuals tend to draw negative conclusions about their general capacity, performance, or worth from such events, which lead to negative self-attributions and ultimately depressive symptoms.

Beck (2005) Beck, 2005; Beck, 2011 also identified that people may have negative core beliefs about others, such as "people are not trustworthy" and "people will hurt me," which contributes to a negative, rigid, and overgeneralized perception of others. People with negative core beliefs about others often view other people as demeaning, uncaring, hurtful, threatening, and manipulative. Individuals who have negative representations about others are overly concerned with avoiding harm from other people (Fraley, Davis, \& Shaver, 1998; Pietromonaco \& Feldman Barrett, 2000), and a sign of harm is sufficient to cause anxiety. These individuals tend to blame others and not themselves for the occurrence of negative events, which are less likely to generate symptoms of depression (Abramson, Seligman, \& Teasdale, 1978; Alloy et al., 2008; Morley \& Moran, 2011).

Based on what has been discussed, we expect negative core beliefs about the self to be associated with anxiety and depression, whereas negative core beliefs about others might be related more closely to anxiety.

\section{Core Beliefs and Attachment Styles}

While core beliefs have received relatively little attention in the scholarly literature, attachment styles have received widespread theoretical and empirical attention. Attachment style is defined as a relatively stable pattern of emotions, behavior, and expectations for close relationships developed because of childhood experiences with caregivers (Fraley \& Shaver, 2000; Hazan \& Shaver, 1987). It is hypothesized that, from these experiences, children develop attachment representations (i.e., beliefs) of both themselves and their caregivers, which serve as a prototype for subsequent social relationships (Bowlby, 1973). This means that individual differences in attachment styles could be understood as differences in the types of core beliefs people have about themselves and about others (see Platts, Tyson, \& Mason, 2002).

Research indicates that the individual differences in attachment styles can be measured along two orthogonal dimensions: attachment-related anxiety and attachment-related avoidance (Brennan, Clark, \& Shaver, 1998; Mikulincer, Shaver, Gillath, \& Nitzberg, 2005). People who score high on the anxiety dimension usually rely on others to provide assurance of their worth and often worry about the availability and responsiveness of the partner, meaning they have negative core beliefs about themselves. However, people who score high on the avoidance dimension tend to be suspicious of their partners and to avoid relationships to protect themselves, which indicates that they have negative core beliefs about others. In this sense, we expect that attachment-related anxiety is associated with negative core beliefs about the self, and attachment-related avoidance is associated with negative core beliefs about others.

\section{Primary Aims of the Present Research}


Mikulincer, Shaver, Gillath, \& Nitzberg, (2005, p. 818) asserted that "scores of studies have shown that a person's attachment style, assessed with fairly simple, two-dimensional self-report measures, is a powerful predictor of various psychological phenomena." However, researchers have been facing difficulties in establishing relationships between different types of attachment and psychopathology, that is, in establishing a complete model of psychopathologies based exclusively on the attachment theory (Platts, Mason, \& Tyson, 2005). This difficulty may be due to attachment theory having a narrow focus of research in regard to categories of beliefs. When researching the dimension of attachment-related anxiety, for example, one might be preponderantly capturing beliefs of the category of unlovabilty - a category that in itself can explain the concern with the availability and responsiveness of the romantic partner, which is characteristic of this attachment style.

We suggest that overcoming of this limitation can be achieved by measuring a larger number of core belief categories. In this sense, we seek to develop an instrument that, similar to attachment measures, not only evaluates two dimensions of negative relational representations (self and others) but also evaluates subdimensions of these representations (categories of negative core beliefs about the self, specifically). We intend, therefore, to offer an instrument capable of preserving the good performance shown by attachment measures in predicting several general psychological phenomena, and also capable of capturing particularities of the clinical phenomenon. In addition, with this study, we intend to provide a well-validated measure of core beliefs, and empirical support for this construct.

\section{Method}

\section{Participants}

Participants were recruited using a snowball sampling method. In this sense, calls for research participation were placed via email and Facebook to friends and colleagues of the principal investigator, inviting them to respond and then disseminate the research through their own network. A caveat that must be addressed is that snowball sampling may sometimes be considered a somewhat biased sampling technique given that it does not randomly select individuals, doing so on the basis of social networks (Browne, 2005). Listwise deletion of missing cases was performed so that only those who answered all the items in the questionnaires were included in the analysis. Accordingly, final analyses included a sample of 1,083 participants. Participants were at least 18 years old $(M=28.7, S D=10.7)$, most were female $(77.6 \%)$ and had completed high school (97.8\%), and the majority were from the Northeast region of Brazil (63.2\%). A subset of 159 participants who provided their email addresses participated in a retest study 2 months after the first data collection.

This study was approved by the ethics committee of the Federal University of Bahia, Brazil, and all participants agreed to a consent form before taking part in this research.

\section{Measures}

Negative Core Beliefs Inventory (NCBI). The NCBI was developed to assess negative core beliefs, as outlined by Beck (2005). We summarized the beliefs discussed by the author and clustered them into the domains mentioned in the "Introduction" section. Afterward, behavioral descriptions provided by the author for each core belief were then adapted to the structure of an inventory item. As an example of the item development process, the belief "I am worthless" is represented by the item "I feel I have little value as a person." The goal was to build items as concrete descriptions of a belief that was defined in abstract. A total of 50 items were developed using the referred strategy, 29 relating to negative core beliefs about the self (nCB-S) and 21 relating to negative core 
beliefs about others (nCB-O). The greater number of items in the nCB-S dimension is justified by the fact that it contains subdimensions, which makes it more complex and therefore requires a more extensive evaluation. Each item is scored on a 4-point Likert scale, ranging from 1 (i.e., "Does not describe me well") to 4 (i.e., "Describes me very well"). There are no labels for anchors "2" and "3."

Young's Schema Questionnaire - Short Version (YSQ-S2; Young, 2003). The YSQ-S2 is a self-report inventory designed to assess 15 types of schemas. This measure was adapted for Brazilian respondents by Cazassa and Oliveira (2012), who obtained a coefficient alpha of $\alpha=$ .95 in their sample. In our sample, the coefficient alpha for this instrument was $\alpha=.92$. We administered items from five scales that were most conceptually related to the beliefs assessed by the NCBI: (a) mistrust/abuse, (b) shame/defectiveness, (c) failure, (d) dependence/incompetence, and (e) vulnerability to harm or illness.

Hospital Anxiety and Depression Scale (HADS; Zigmond \& Snaith, 1983). The HADS is a 14-item self-report inventory that assesses symptoms of anxiety and depression. The version used in the present study was adapted and validated for Brazilian respondents by Botega, Bio, Zomignani, Garcia, and Pereira, (1995), who obtained coefficient alphas in their sample of $\alpha=$ .68 or depression and $\alpha=.77$ for anxiety.

Experiences in Close Relationships - Short Version (ECR-R; Brennan et al., 1998). The ECR-R is a 10 -item self-report inventory that assesses attachment-related avoidance and attachment-related anxiety. The scale was adapted and validated for Brazilian respondents by Natividade and Shiramizu (2015), who obtained an alpha coefficient of $\alpha=.73$ in their sample. In our sample, the coefficient alpha for this instrument was $\alpha=.67$.

Sociodemographic Questionnaire. The sociodemographic questionnaire included items regarding personal characteristics, age, gender, marital status, race, siblings, religious preference, region of residence in Brazil, and highest level of education. Furthermore, the sociodemographic questionnaire included 10 items assessing experiences and perceptions of the respondent's childhood, as follows: (a) "Were you bullied at school by peers or teachers?"; (b) "Did your parents split up when you were a child?"; (c) Were you orphaned or abandoned as a child?"; (d) "Did your parents fight a lot?"; (e) "Did your parents leave the home for work when you were a child?"; (f) "Were your parents controlling?"; (g) "Did your parents yell at you?"; (h) "Did your parents criticize you?"; (i) "Did your parents beat you?"; and (j) “Were your parents emotionally cold?". Those items were devised based on childhood experiences that the literature commonly associates with negative core beliefs (Bowlby, 1973; Beck, 2011). The goal of the questions was to explore possible relationships between the NCBI scores and negative experiences during childhood, guiding future and more detailed research. The sociodemographic instrument was devised by the authors for use in this study and there is no research on the measure's psychometric properties.

\section{Data Analysis}

Content Validity. NCBI items were judged by five experienced cognitive behavioral therapists in terms of (a) their relevance to Beck's (2005) scheme of core beliefs, and (b) whether items indeed measured CB-Ss or CB-Os. Judges provided binary (yes/no) responses for each item. Items for which there was below $80 \%$ rater disagreement were excluded from the final measure. Judges also suggested small changes to the wording of some items. After incorporating judges' suggestions, a pilot study was conducted with a small group of participants to examine whether they could clearly understand the wording of the items and whether any other changes in the instrument were needed. Responses from these participants were used to refine the measure but were not considered in the data analysis reported in the present study.

Exploratory Factor Analysis (EFA). Measures of skewness and kurtosis were used to verify normality of NCBI scores. Absolute values below 1 are indicative of normality (George \& Mallery, 
2010). Three assumptions of factor analytic models were tested prior to fitting the exploratory model: (a) Kaiser-Meyer-Olkin's (KMO) measure of sample adequacy, with values above .60 considered satisfactory (Dziuban \& Shirkey, 1974); (b) Bartlett's sphericity test (Bartlett, 1973), which should produce significant $p$ values; and (c) the assessment of whether the determinant of the correlation matrix is different from zero. All EFAs were performed using the minimum residuals (minres) estimation algorithm with a promax rotation. Two criteria were adopted to verify model adequacy: (1) the amount of variance explained by the factor solution, and (2) whether the items loaded onto their expected factors with factor loadings above .30. Items that did not meet the second criterion were excluded from the measure (Miller, Lovler, \& MacIntire, 2013). To investigate the existence of subdimensions in the scale, EFA was again performed for each of the factors. The same procedures and criteria were used to interpret the factor solution. EFA models were fitted using the psych package of the R software (Revelle, 2015).

Confirmatory Factor Analysis (CFA). The findings of the EFA in which dimensions and subdimensions were identified were used to build the confirmatory models fitted under Structural Equation Models (SEM). A Pearson correlation matrix and the Maximum Likelihood (ML) estimation algorithms were used for all the models tested in this study. Five goodness-of-fit measures were computed: RMSEA, CFI, GFI, NNFI, and a $\chi^{2}$ test. Satisfactory models must display RMSEA below .08, and CFI, GFI, and NNFI above .90. Significant $p$ values for the chi-squared test are indicative of lack of fit, although there is substantial chance of Type I errors when larger samples are used (Weston \& Gore, 2006).

Modification indices that suggested estimating the correlation between the residuals of items that are expected to belong to the same dimension and descriptor were taken into account so as to improve the model. This scenario suggests that the degradation observed in fit measures was caused by collinearity (redundancy) between items. An iterative algorithm that used the area under the item information curve obtained from a Graded Response Model (GRM, Samejima, 1969) was applied to select between redundant items suggested by the CFA. In the context of GRM, the amount of information an item provides is not uniformly distributed over the latent trait, being, instead, a function of the ability parameter. Hence, it is possible to verify how much an item contributes to the increase in precision of the ability estimate through the size of the area under the information curve. Therefore, the redundant item with the bigger area under the curve was retained. CFA procedures were performed in the ltm (Rizopoulos, 2006) and lavaan (Rosseel, 2012) R packages.

Item Response Theory (IRT). According to IRT, unidimensionality and local independence in the set of modeled items are assumed. Per the results from the EFA (described in the subsequent "Results" section), a unidimensional subscale was devised for nCB-O and for each of the four subdimensions of nCB-S and tested for IRT assumptions using lavaan (Rosseel, 2012). The nCB-S subscale is not presumed unidimensional, which is why an IRT model was not fit to that group of items as a whole. Also, because RMSEA is too sensitive to models with small degrees of freedom, Standardized Root Mean Square Residual (SRMR) was used instead, which performs better under those circumstances (Chen, Curran, Bollen, Kirby, \& Paxton, 2008). All other previously mentioned model fit indices used in the CFA were also computed as evidence for unidimensionality. Residual correlations above .30 in absolute value were used as indicators of local independence (Smith, 2002).

The Graded Response Model (GRM; Samejima, 1969) and the Generalized Partial Credit Model (G-PCM; Muraki, 1992) were fit to the subscales. Within model comparisons (constrained and unconstrained) were performed using a chi-squared Likelihood Ratio Test (LRT) for nested models. Constrained and unconstrained models were both tested so as to check whether the models with equal discrimination parameters across items had a better fit than those whose discrimination parameters had to be estimated. Significant $\mathrm{p}$ values are desired because they indicate that the increase in model complexity is compensated by a sufficient increase in model accuracy. 
Between-model comparison was done through a chi-squared test of expected and observed frequencies of responses in two- and three-way contingency tables. The number of misfitting pairs and triples of items is tallied for each model and the one with the smaller count is deemed the best model.

IRT also allows for individual item quality assessment, which was done through the analysis of the discrimination parameters and the item characteristic and item information curves. Items with discrimination values below 1.0 were excluded (DeMars, 2010). The percentage of the area under the information curve at the first and second half (low and high abilities, respectively) of the latent trait continuum is assessed separately for each sub-dimension. This analysis provides information as to whether greater precision in the instrument scores are obtained for high or low ability individuals.

Comparisons with Other Measures. Scores on the NCBI were compared with scores on other measures to determine convergent, discriminant, and criterion-related validity. First, convergent validity was assessed by: (a) correlating $\mathrm{nCB}-\mathrm{S}$ with attachment-related anxiety via the ECR-R, depression via the HADS, anxiety via the HADS, and the sum of the subscores for the schemas of shame/defectiveness, failure, dependence/incompetence, and vulnerability to harm or illness via the YSQ-S2; and (b) correlating nCB-O with attachment-related avoidance via the ECR-R, anxiety via the HADS, and the mistrust/abuse schema via the YSQ-S2. Second, discriminant validity was assessed using a series of regressions that used depression as the dependent variable. Regression coefficients for $\mathrm{nCB}-\mathrm{O}$ were compared between a univariate regression predicting depression and a multiple regression incorporating both nCB-O and nCB-S to predict depression. A reduction in betas was expected once the association with depression was controlled by the scores in nCB-S. All variables used in the model were numeric and were standardized before its parameter estimation. Finally, criterion validity was assessed by comparing the scores of nCB-S and nCB-O with answers to questions concerning negative childhood experiences using multiple regression models, with a backward stepwise regression method for variable selection.

Reliability. Internal consistency was evaluated by calculating coefficient alphas. Test-retest reliability was assessed via correlations between the individual total scores for the initial administration and the retest (McCrae, Kurtz, Yamagata, \& Terracciano, 2011).

\section{RESULTS}

\section{Content Validity}

Four NCBI items were excluded due to disagreement among judges. Building on judges' suggestions, a few wording modifications were performed so as to improve the quality of some items. During the pilot study, no participant reported difficulty in answering any of the items, and, therefore, no new modifications were made to the NCBI pilot version. The final version of the NCBI consisted of 27 items for nCB-S and 19 for nCB-O.

\section{Exploratory Factor Analysis (EFA)}

Skewness (0.698) and kurtosis (-0.339) were both within the accepted bounds to support the assumption that scores as normally distributed. The KMO (.97), Bartlett's sphericity test ( $p<$ $.001)$, and determinant of the correlation matrix $(>0)$ provided evidence that the EFA assumptions were met. As such, the Pearson correlation matrix was used for the EFA model.

To determine the factor structure of the measure, a two-dimensional EFA model was fitted. Table 1 displays the factor loadings for the model. The two-factor solution was supported, with $45 \%$ of the total variance explained, only slightly below the $50 \%$ threshold recommended by Miller et al. (2013). With the exception of item nCB-O5, items loaded onto their respective 
TABLE 1. Results From the Two-Dimensional Exploratory Factor Analysis

\begin{tabular}{|c|c|c|}
\hline Item & Factor 1 & Factor 2 \\
\hline nCB-S14: "I think I don't measure up to others." & 0.88 & \\
\hline nCB-S3: "I feel incompetent in most things I do." & 0.84 & \\
\hline nCBS-2: "I feel like other people are more competent than I am." & 0.84 & \\
\hline nCB-S26: "I feel insignificant." & 0.77 & \\
\hline nCB-S4: "Even if I put an effort my results will be bad." & 0.75 & \\
\hline nCB-S17: "I think it is unlikely that someone will be attracted to me." & 0.74 & \\
\hline nCB-S15: “Taking everything into account, I think I'm a failure.” & 0.74 & \\
\hline nCB-S13: "I feel inferior to some people." & 0.74 & \\
\hline $\begin{array}{l}\text { nCB-S19: "I feel like I will always be rejected when my flaws are per- } \\
\text { ceived." }\end{array}$ & 0.74 & \\
\hline nCB-S21: "I think I'm not good enough to be loved." & 0.73 & \\
\hline nCB-S18: "I feel I'm boring or uninteresting." & 0.73 & \\
\hline nCB-S23: "I feel I have little value as a person." & 0.71 & \\
\hline nCB-S16: "I think it's difficult for someone to like me." & 0.70 & \\
\hline nCB-S5: "I feel incapable of changing my life." & 0.67 & \\
\hline nCB-S1: "I feel bad for not fitting in." & 0.65 & \\
\hline $\begin{array}{l}\text { nCB-S20: "I feel that I will hardly ever have the love or friendship I } \\
\text { would like from others." }\end{array}$ & 0.63 & \\
\hline nCB-S8: "I feel a sense of insecurity most of the time." & 0.61 & \\
\hline nCB-S27: "I think the world would be better if I didn't exist." & 0.57 & \\
\hline nCB-S6: "I feel unprotected regarding life’s difficulties." & 0.56 & \\
\hline $\begin{array}{l}\text { nCB-S12: "I feel intimidated in the presence of someone more success- } \\
\text { ful than me" }\end{array}$ & 0.55 & \\
\hline nCB-S9: "I feel weak when I face adversity or a setback." & 0.55 & \\
\hline nCB-O5: "I'm afraid to expose myself in public and being ridiculed." & 0.51 & \\
\hline nCB-S7: "I feel helpless when I find myself alone." & 0.48 & \\
\hline nCB-S24: "I think my presence is harmful to others." & 0.47 & \\
\hline nCB-S22: "I think nobody loves me." & 0.46 & \\
\hline $\begin{array}{l}\text { nCB-S10: "I need someone I trust nearby when facing new situa- } \\
\text { tions." }\end{array}$ & 0.43 & \\
\hline $\begin{array}{l}\text { nCB-S11: "I feel the need of someone's help for taking day to day deci- } \\
\text { sions." }\end{array}$ & -0.38 & \\
\hline nCB-S25: "I think I am evil inside." & 0.37 & \\
\hline $\begin{array}{l}\text { nCB-O16: "In many situations I feel that people want to take advan- } \\
\text { tage of me." }\end{array}$ & & 0.88 \\
\hline $\begin{array}{l}\text { nCB-O11: "I think people don't worry about hurting me in order to } \\
\text { get what they need." }\end{array}$ & & 0.84 \\
\hline nCB-O17: "I fear being exploited when people ask me for favors." & & 0.74 \\
\hline nCB-O15: "I think people want me to fail." & & 0.71 \\
\hline $\begin{array}{l}\text { nCB-O7: "I think people don't worry about saying something that } \\
\text { might hurt me." }\end{array}$ & & 0.69 \\
\hline nCB-O9: "I feel that people hurt me on purpose." & & 0.65 \\
\hline $\begin{array}{l}\text { nCB-O18: "I feel that people try to impose their ideas or opinions on } \\
\text { me." }\end{array}$ & & 0.64 \\
\hline $\begin{array}{l}\text { nCB-O4: "I think that people would deny helping me in case I was in } \\
\text { need." }\end{array}$ & & 0.64 \\
\hline
\end{tabular}


TABLE 1. CONTINUED

\begin{tabular}{|c|c|c|}
\hline Item & Factor 1 & Factor 2 \\
\hline nCB-O10: "I feel I need to protect myself from others." & & 0.60 \\
\hline nCB-O19: "I feel that people try to meddle in my life." & & 0.59 \\
\hline nCB-O3: "I think people try to avoid me when I ask for something." & & 0.58 \\
\hline nCB-O12: "I'm afraid to be betrayed even by someone I trust." & & 0.56 \\
\hline nCB-O6: "I think people enjoy exposing me to ridicule." & & 0.55 \\
\hline $\begin{array}{l}\text { nCB-O14: "When someone criticizes me I feel that he or she is trying } \\
\text { to attack me." }\end{array}$ & & 0.55 \\
\hline $\begin{array}{l}\text { nCB-O2: "I think that people don't care about me when I am going } \\
\text { through a rough patch." }\end{array}$ & & 0.53 \\
\hline nCB-O13: "I'm afraid to lend my things even to a friend." & & 0.50 \\
\hline $\begin{array}{l}\text { nCB-O1: "I don't think people pay attention when I talk about my } \\
\text { problems." }\end{array}$ & & 0.46 \\
\hline $\begin{array}{l}\text { nCB-O8: "I am afraid to open up to people and that they'll end up } \\
\text { playing with my feelings." }\end{array}$ & & 0.46 \\
\hline
\end{tabular}

Note. nCB-O = Negative Core Beliefs about Others; nCB-S = Negative Core Beliefs about the Self; Only leadings above .3 are displayed.

factors. The minimum factor loading was .37. Hence, item nCB-O5 (i.e., "I'm afraid to expose myself in public and being ridiculed") was the only item excluded at this point.

A theory-driven exploratory three-factor solution was initially tested to evaluate subdimensions nCB-S: helplessness, unlovability, and worthless (cf. Beck, 2005). Results indicated that the items on the helplessness dimension (i.e., items nCB-S1-15) split into two factors, suggesting its heterogeneity. On the basis of item content, the items were grouped according to two central themes: (a) Helplessness/Inferiority (HIN; e.g., "I feel inferior to some people"); and (b) Helplessness/Vulnerability (HVU; e.g., "I feel weak when facing adversities or setbacks"). The label "helplessness" was to both subdimensions to emphasize their common theoretical origin. The subdimensions, unlovability (UNL; items nCB-S16-22) and worthlessness (WOR; nCB-S23-27), combined as a single dimension. Although this solution accounted for by an adequate percentage of total explained variance (54\%), it was not supported by theory, which prompted the test of a four-factor solution.

The four-factor solution accounted for $57 \%$ of variance, and it is theoretically sound in light of the separation between the unlovability and worthlessness dimensions. Most the items adequately loaded onto their respective dimensions. Item nCB-S1 (i.e., "I feel bad for not fitting in") did not load onto any of the subfactors, which led to its deletion. Items nCB-S5 (i.e., "I feel incapable of changing my life") and nCB-S15 (i.e., "Taking everything into account, I think I am a failure") were initially designed to load onto HIN, but they loaded ultimately onto WOR. Because these items measure central beliefs about the self that are highlighted in scholarly accounts of cognitive theory and observed regularly in clinical practice, we made the final decision to retain these items in the WOR scale.

In contrast, a single nCB-O factor was retained for three reasons. First, there is no theoretical justification to separate $\mathrm{nCB}-\mathrm{O}$ factors in the way that there is for separate $\mathrm{nCB}-\mathrm{S}$ factors. Second, all items in the one-factor displayed factor loadings above .41 and $42 \%$ of explained variance. Third, EFAs run with more than one factor resulted in forced dimensions that contained very few items.

\section{Confirmatory Factor Analysis (CFA)}


TABLE 2. Fit Indices of Confirmatory Factor Analysis Models

\begin{tabular}{llllllll}
\hline Removed & RMSEA & CFI & GFI & NNFI & $\chi 2$ & $d f$ & $p$ \\
\hline Baseline & 0.068 & 0.850 & 0.794 & 0.842 & 5343.826 & 897 & $<.001$ \\
nCBO-1 & 0.066 & 0.857 & 0.804 & 0.849 & 4948.573 & 855 & $<.001$ \\
HIN12 & 0.066 & 0.864 & 0.812 & 0.856 & 4609.442 & 814 & $<.001$ \\
nCB-O19 & 0.065 & 0.870 & 0.818 & 0.862 & 4314.085 & 774 & $<.001$ \\
nCB-O17 & 0.064 & 0.876 & 0.826 & 0.868 & 4016.852 & 735 & $<.001$ \\
HVU11 & 0.064 & 0.881 & 0.831 & 0.874 & 3768.354 & 697 & $<.001$ \\
nCB-O4 & 0.063 & 0.885 & 0.839 & 0.878 & 3531.351 & 660 & $<.001$ \\
HIN4 & 0.063 & 0.889 & 0.845 & 0.881 & 3305.063 & 624 & $<.001$ \\
nCB-O2 & 0.062 & 0.894 & 0.851 & 0.887 & 3051.697 & 589 & $<.001$ \\
WOR25 & 0.062 & 0.898 & 0.856 & 0.890 & 2880.942 & 555 & $<.001$ \\
nCB-O6 & 0.062 & 0.902 & 0.862 & 0.894 & 2683.961 & 522 & $<.001$ \\
UNL17 & 0.062 & 0.902 & 0.865 & 0.894 & 2541.242 & 490 & $<.001$ \\
Item Response Theory & & & & & & \\
nCBO-13 & 0.063 & 0.904 & 0.866 & 0.897 & 2434.256 & 459 & $<.001$ \\
\hline
\end{tabular}

Note. To obtain the area under the information curve through IRT, unidimensional models (GRM; Samejima, 1969) were fit to each of the four subdimensions of nCB-S and to nCB-O. nCB-O = Negative Core Beliefs about Others; $\mathrm{nCB}-\mathrm{S}=$ Negative Core Beliefs about the Self; HIN = Helplessness/Inferiority; HVU = Helplessness/Vulnerability; UNL = Unlovability; WOR $=$ Worthlessness.

A second-order model with four sub-factors for nCB-S was then tested in a CFA framework. Based on the modification indices calculated for this model, we observed that the changes resulting in greatest increase in fit were obtained by estimating the residual correlation of items that could be interpreted as theoretically redundant. They all belonged to the same dimension and mostly to the same descriptor. This scenario justified the partial acceptance of the suggestions from the modification indices expressed in one of the items being removed. To decide between a pair of problematic items, the one that maximized the area under the information curve in the GRM model was kept. Table 2 presents all 12 iterations of the process with the removed item and the correspondent increase in model performance. The final results of this process are in accordance with the acceptance thresholds regarding the fit measures described in the "Methods" section $\left(\mathrm{RMSEA}=.062\right.$, CFI $=.902, \mathrm{GFI}=.865$, NNFI $\left.=.894, \chi^{2}=2541.242, d f=490, p<.001\right)$. Thus, the fit measures indicate good model-data adequacy.

\section{Item Response Theory (IRT)}

The structural equation unidimensional models provided enough evidence to meet the assumption of unidimensionality to fit IRT models. The fit measures attained satisfactory results, and there are no residual correlations above .30 .

All LRTs were significant $(p<.001)$, which implies that within models, all the unconstrained versions fit the data better than their constrained counterparts. The two- and three-way tables signaled a coherent trend overall, and for all unconstrained models, the GRM had a smaller number of misfit item pairs or triplets than the GPCM. The number of flagged pairs and triplets of items, respectively, for the GRMs for each of the subscales were $\mathrm{CBO}=(2,0), \mathrm{HIN}=(0,0), \mathrm{HVU}=(0$, $0), \mathrm{UNL}=(0,0)$, and WOR $=(0,0)$. The GPCMs had $\mathrm{CBO}=(4,2), \mathrm{HIN}=(4,3), \mathrm{HVU}=(0$, $0), \mathrm{UNL}=(1,0)$, and WOR $=(1,0)$, pairs and triplets, respectively, of flagged items. Hence, the number of flagged items is very small, suggesting good fit. 
Discrimination parameters ranged from 0.94 (nCB-O13) to 3.86 (WOR26), which indicates that items are overall related to their respective construct and perform well in the process of estimating the latent trait, providing further evidence of validity to the scale.

Table 3 summarizes the discrimination and information values for each item, as well as the percentage of the area under the information curve that is in each half of the latent trait continuum for each subdimension. The overall trend is that the subscales provide more precise estimation of ability for individuals with higher levels of the latent traits. This is an expected result because the scale was designed to measure only dysfunctional behavioral representations about the self and others.

Due to the fact that the item nCBO-013 ("I am afraid to lend my things even to a friend.") presented a discrimination parameter lower than 1 , it was hence removed from the model. This decision was also based on the analysis of the Item Characteristic Curve (ICC) of this item, which revealed redundancy of categories two and three, given that these were not the most likely to be endorsed in any interval of the latent trait (i.e., revealed lack of fit of this item to the model).

Another CFA model was fit after removing item CBO13, which improved all measures of fit, further justifying its deletion from the scale. The final values for the fit indices were: RMSEA $=$ $.063, \mathrm{CFI}=.904, \mathrm{GFI}=.866, \mathrm{NNFI}=.897, \chi^{2}(490)=2434.256, p<.001$. The final structure of the scale, with item loadings and error measures, is displayed in Figure 1.

\section{Comparisons Comparisons WWwWith Other MeasuresIth Other Measures}

Analyses described in this section were performed with the final version of the scale, containing a total of 32 items, 21 for the nCB-S dimension and 11 for the nCB-O dimension.

Convergent Validity. Table 4 displays correlations of nCB-S and nCB-O with additional measures with which they were expected to be associated. There were significant correlations between nCB-S scores and anxiety and depression. The scores from the nCB-O scale correlated significantly with symptoms of anxiety. This followed the expected correlation structure described in the "Methods" section. Scores from the nCB-S scale correlated positively with the sum of scores from the shame/defectiveness, failure, dependence/incompetence, and vulnerability to harm scales of the YSQ-S2, and nCB-O correlated positively with the mistrust scale of the YSQS2. Also as expected, nCB-O correlated positively with attachment-related avoidance, and nCB-S correlated positively with attachment-related anxiety.

Discriminant Validity. Table 5 displays results from the univariate and multiple regressions employed to establish the NCBI's discriminant validity. As predicted, the beta coefficient of nCB-O was greatly reduced when nCB-S was included in a multiple regression predicting depression as the dependent variable. In other words, when nCB-S scores were held constant, nCB-O's effect on depression was reduced.

Criterion Validity. Table 6 summarizes data from a series of regressions that aimed to establish the NCBI's criterion validity. As expected, negative experiences in childhood, including bullying, parents working out of the home, parents being regarded as controlling, parents being regarded as judgmental, and parents being regarded as cold, were associated with increased scores in both dimensions of core beliefs.

Reliability. Table 7 displays data for two measures of reliability: coefficient alpha and testretest reliability. All alpha coefficients are above .84, and all correlations are above .78 .

\section{Discussion}

We believe that the data presented here represent an important step in establishing a reliable and valid measurement of a construct in cognitive theory that has been relatively neglected to date. 


\section{TABLE 3. ITEM ReSPONSE TheORY}

\begin{tabular}{|c|c|}
\hline Item & Discrimination (Information) \\
\hline \multicolumn{2}{|c|}{ Core Beliefs about Others (CBO) } \\
\hline nCB-O 3 & $1.99(3.39)$ \\
\hline nCB-O 7 & $2.16(3.04)$ \\
\hline nCB-O 8 & $1.77(1.91)$ \\
\hline nCB-O 9 & $2.87(5.44)$ \\
\hline nCB-O 10 & $2.03(2.61)$ \\
\hline nCB-O 11 & $2.21(3.16)$ \\
\hline nCB-O 12 & $1.60(1.61)$ \\
\hline nCB-O 13 & $0.94(1.18)$ \\
\hline nCB-O 14 & $1.47(1.94)$ \\
\hline nCB-O 15 & $1.92(3.42)$ \\
\hline nCB-O 16 & $2.06(3.07)$ \\
\hline nCB-O 18 & $1.52(2.02)$ \\
\hline Information, $\%(-\infty, 0)$ & $11.69 \%-26.27 \%$ \\
\hline Information, $\%(0, \infty)$ & $32.8 \%-73.73 \%$ \\
\hline \multicolumn{2}{|l|}{ Helplessness/Inferiority (HIN) } \\
\hline HIN 2 & $3.09(4.24)$ \\
\hline HIN 3 & $2.57(4.41)$ \\
\hline HIN 13 & $2.75(3.54)$ \\
\hline HIN 14 & $3.85(6.10)$ \\
\hline Information, $\%(-\infty, 0)$ & $9.68 \%-34.61 \%$ \\
\hline Information, $\%(0, \infty)$ & $18.29 \%-65.39 \%$ \\
\hline \multicolumn{2}{|c|}{ Helplessness/Vulnerability (HVU) } \\
\hline HVU 6 & $2.01(2.67)$ \\
\hline HVU 7 & $2.19(3.11)$ \\
\hline HVU 8 & $2.50(3.29)$ \\
\hline HVU 9 & $2.44(3.57)$ \\
\hline HVU 10 & $1.55(1.71)$ \\
\hline Information, $\%(-\infty, 0)$ & $8.29 \%-36.6 \%$ \\
\hline Information, $\%(0, \infty)$ & $14.35 \%-63.4 \%$ \\
\hline \multicolumn{2}{|l|}{ Unlovable (UNL) } \\
\hline UNL 16 & $3.27(6.42)$ \\
\hline UNL 18 & $2.74(4.71)$ \\
\hline UNL 19 & $3.11(5.19)$ \\
\hline UNL 20 & $3.49(6.54)$ \\
\hline UNL 21 & $3.36(6.61)$ \\
\hline UNL 22 & $2.58(4.88)$ \\
\hline Information, $\%(-\infty, 0)$ & $5.10 \%-12.94 \%$ \\
\hline Information, $\%(0, \infty)$ & $34.35 \%-87.06 \%$ \\
\hline \multicolumn{2}{|l|}{ Worthless (WOR) } \\
\hline WOR 5 & $1.86(2.57)$ \\
\hline WOR 15 & $2.58(4.86)$ \\
\hline WOR 23 & $3.47(7.02)$ \\
\hline WOR 24 & $2.42(4.33)$ \\
\hline WOR 26 & $3.86(7.84)$ \\
\hline WOR 27 & $3.36(5.95)$ \\
\hline
\end{tabular}


TABLE 3. CONTINUED

\begin{tabular}{lc}
\hline Item & Discrimination (Information) \\
\hline Information, $\%(-\infty, 0)$ & $2.51 \%-7.16 \%$ \\
Information, $\%(0, \infty)$ & $32.57 \%-92.84 \%$ \\
\hline
\end{tabular}

Note. $\mathrm{nCB}-\mathrm{O}=$ Negative Core Beliefs about Others; HIN = Helplessness/Inferiority; HVU = Helplessness/Vulnerability; UNL = Unlovability; WOR = Worthlessness.

The results of this study provide preliminary evidence that NCBI is a bidimensional measure of negative core beliefs about the self and others. It demonstrated adequate internal consistency and test-retest reliability. The nCB-S dimension separated meaningfully into subdimensions consistent with cognitive theory. Both nCB-S and nCB-O were associated with self-reported emotional distress, which is to be expected because, according to cognitive theory, emotional distress can be understood, in part, by the activation of these beliefs. Moreover, nCB-S and nCB-O were each associated with predicted schemas, as measured by the YSQ-S2, and dimensions of attachment style. They were also associated with some adverse childhood experiences, which is expected per cognitive theory, which proposes that negative core beliefs are formed through key childhood events (Beck, 2011).

However, it is important to note that some of results obtained in validity analyses were not entirely "clean." For example, results from regression analyses that were conducted to establish discriminant validity demonstrated, as expected, that the effect of negative core beliefs about others would be reduced once the variance associated with negative core beliefs about the self was controlled. Nevertheless, even when the variance associated with negative core beliefs about the self was controlled, there was still a significant beta value to capture the effect of negative core beliefs about the self on depression. Moreover, in convergent validity analyses, there was a significant correlation between nCB-O and the depression scale of the HADS.

Furthermore, several limitations of this study must be acknowledged. First, this study used a convenience sample of participants who were recruited through email and social media. The degree to which this sample is representative of the general population is unclear, and it is not a clinical sample of people who struggle with diagnosable depressive and anxiety disorders, for whom

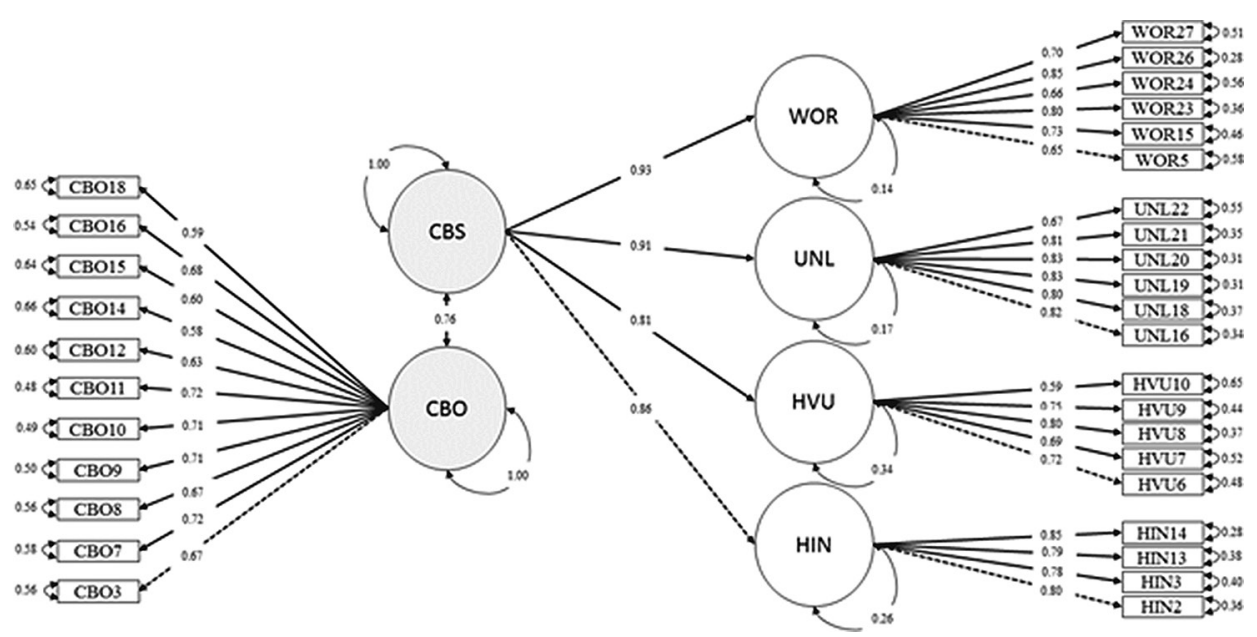

FIGURE 1. Structural model with two dimensions and four subdimensions. 
Table 4. Convergent Validity-Correlation Coefficients Between Psychological MEASURES $^{\text {a }}$

\begin{tabular}{lcccccc}
\hline Dimension & nCB-O & HIN & HVU & UNL & WOR & nCB-S \\
\hline HIN & 0.43 & & & & & \\
HVU & 0.52 & 0.65 & & & & \\
UNL & 0.61 & 0.52 & 0.54 & & & \\
WOR & 0.51 & 0.66 & 0.61 & 0.69 & & \\
nCB-S & 0.62 & 0.84 & 0.85 & 0.81 & 0.85 & \\
Mistrust/abuse & 0.76 & 0.37 & 0.43 & 0.55 & 0.44 & 0.53 \\
Schemas (YSQ-S2) & & & & & & \\
SDDI Schemas (YSQ- & 0.61 & 0.72 & 0.73 & 0.66 & 0.73 & 0.85 \\
S2) & & & & & & \\
Anxiety (HADS) & 0.59 & 0.55 & 0.62 & 0.57 & 0.60 & 0.67 \\
Depression (HADS) & 0.51 & 0.54 & 0.53 & 0.56 & 0.63 & 0.65 \\
Avoidant Attachment & 0.21 & 0.16 & 0.28 & 0.17 & 0.11 & 0.21 \\
Style (ECR-R) & & & & & & \\
Anxious Attachment & 0.44 & 0.37 & 0.47 & 0.46 & 0.34 & 0.47 \\
Style (ECR-R) & & & & & & \\
\hline
\end{tabular}

Note. $\mathrm{nCB}-\mathrm{O}=$ Core Beliefs about Others; $\mathrm{nCB}-\mathrm{S}=$ Core Beliefs about the Self; HIN = Helplessness/Inferiority; HVU = Helplessness/Vulnerability; UNL = Unlovability; WOR = Worthlessness; HADS = Hospital Anxiety and Depression Scale; YSQ-S2 = Young Schema Questionnaire-Short Version; ECR-R = Experiences in Close Relationships-Short Version; $\mathrm{SDDI}=$ Sum of scores from the shame/defectiveness, failure, dependence/incompetence, and vulnerability to harm schemas.

aPearson correlation coefficient; the $p$-values of all correlation coefficients were below .01.

the study measures would be most appropriate. Second, all study variables were obtained via self-report. Self-report relies on insight and honest and accurate responding of the participants who complete such measures, and a study that uses self-report entirely might obtain inflated correlations due to common method variance. Third, the study variables that assessed aversive

TABLE 5. Regression Models for Discriminant Validity: Depression Scores (HADS) AS DePENDENT VARiable

\begin{tabular}{llll}
\hline & $\beta$ & $S E$ & $n$ \\
\hline Model 1 (nCB-O Only) & & & 1082 \\
$\quad$ Intercept & 0 & 0.026 & \\
CBO & 0.506 & $0.026^{* * *}$ & 1082 \\
Model 2 (nCB-O and nCB-S) & & & \\
$\quad$ Intercept & 0 & 0.023 & \\
CBO & 0.115 & $0.032^{* * *}$ & \\
CBS & 0.569 & $0.032^{\star * *}$ & \\
\hline
\end{tabular}

Note. $\mathrm{nCB}-\mathrm{O}=$ Core Beliefs About Others; nCB-S = Negative Core Beliefs About the Self $* * * p<.001$. 
TABle 6. Results of Backward Stepwise Multiple Regression Analyses for nCB-O and nCB-S for the Assessment of Criterion Validity Using Childhood Experiences as Covariates

\begin{tabular}{|c|c|c|c|c|c|}
\hline \multirow{2}{*}{$\begin{array}{l}\text { Variable Level } \\
\text { Bullying_Baseline: No }\end{array}$} & \multicolumn{2}{|c|}{$\beta(\mathrm{nCB}-\mathrm{O}) \mathrm{SE}(\mathrm{nCB}-\mathrm{O})$} & \multirow[t]{2}{*}{$\mathrm{B}(\mathrm{nCB}-\mathrm{S})$} & \multicolumn{2}{|c|}{$\mathrm{SE}(\mathrm{nCB}-\mathrm{S}) n$} \\
\hline & & & & & \\
\hline Yes & 0.33 & $0.04^{* * *}$ & 0.25 & $0.04^{\star * *}$ & 437 \\
\hline Does not remember & 0.20 & $0.06^{* * *}$ & 0.20 & $0.06^{\star * *}$ & 139 \\
\hline \multicolumn{6}{|c|}{ Parents left to work in the subject childhood-Baseline: Neither } \\
\hline Only the mother & 0.16 & 0.12 & 0.22 & 0.12 & 36 \\
\hline Only the father & -0.08 & 0.07 & 0.08 & 0.07 & 356 \\
\hline Both & 0.01 & 0.07 & 0.18 & $0.07^{\star \star}$ & 589 \\
\hline Does not remember & -0.14 & 0.18 & -0.15 & 0.17 & 14 \\
\hline \multicolumn{6}{|c|}{ Controlling Parents-Baseline: Neither } \\
\hline Only the mother & 0.14 & $0.05^{\star}$ & 0.12 & $0.05^{\star}$ & 229 \\
\hline Only the father & 0.11 & 0.07 & 0.08 & 0.06 & 128 \\
\hline Both & 0.21 & $0.05^{\star * *}$ & 0.13 & $0.05^{\star \star}$ & 288 \\
\hline Does not remember & 0.17 & 0.09 & 0.15 & 0.08 & 61 \\
\hline \multicolumn{6}{|c|}{ Judgmental Parents - Baseline: Neither } \\
\hline Only the mother & 0.13 & $0.06^{*}$ & 0.08 & 0.06 & 168 \\
\hline Only the father & 0.07 & 0.07 & -0.04 & 0.07 & 101 \\
\hline Both & 0.25 & $0.05^{\star \star \star}$ & 0.18 & $0.05^{\star * *}$ & 255 \\
\hline Does not Remember & 0.22 & $0.07^{\star *}$ & 0.18 & $0.07^{\star}$ & 89 \\
\hline \multicolumn{6}{|c|}{ Variable: Cold Parents-Baseline: Neither } \\
\hline Only the mother & 0.04 & 0.08 & 0.17 & $0.07^{\star}$ & 73 \\
\hline Only the father & 0.19 & $0.05^{\star * *}$ & 0.15 & $0.05^{\star \star}$ & 180 \\
\hline Both & 0.28 & $0.06^{* * *}$ & 0.33 & $0.05^{\star * *}$ & 149 \\
\hline Does not remember & 0.32 & $0.09^{* * *}$ & 0.33 & $0.09^{* * *}$ & 54 \\
\hline
\end{tabular}

Note. $\mathrm{nCB}-\mathrm{O}=$ Negative Core Beliefs About Others; $\mathrm{nCB}-\mathrm{S}=$ Negative Core Belief About the Self; $\mathrm{nCB}-\mathrm{O}$ adjusted $\mathrm{R}^{2}=.27$; $\mathrm{nCB}-\mathrm{S}$ adjusted $\mathrm{R}^{2}=.34{ }^{\star}{ }^{\star} p<.05 ;{ }^{\star \star} p<.01 ;{ }^{\star \star \star} p<.001$.

TABLE 7. ReLIABILITIES

\begin{tabular}{lll}
\hline Dimension & Coefficient Alpha & Test-Retest \\
\hline nCB-O & .89 & .82 \\
nCB-S & .95 & .86 \\
HIN & .89 & .84 \\
HVU & .84 & .81 \\
UNL & .91 & .78 \\
WOR & .87 & .82 \\
\hline
\end{tabular}

Note. $\mathrm{nCB}-\mathrm{O}=$ Negative Core Beliefs about Others; $\mathrm{nCB}-\mathrm{S}$ = Negative Core Beliefs about the Self; HIN = Helplessness/Inferiority; HVU = Helplessness/Vulnerability; UNL = Unlovability; WOR $=$ Worthlessness. 
childhood experiences were developed for the purpose of the study and have not themselves been subject to psychometric scrutiny.

We, then, encourage future research to: (a) establish the psychometric properties of the measure in clinical samples of clients with depressive and anxiety disorders; (b) examine associates with other constructs important in cognitive theory, such as automatic thoughts and cognitive distortions; (c) establish the power of the NCBI to predict other relevant psychological phenomena, such as emotion dysregulation and quality of relationships; and (d) determine the degree to which scores on the NBCI shift as a function of successful treatment with CBT.

Although more work is needed to establish the psychometric properties of NCBI, it is important to note a potential utility of this measure for the field of cognitive psychology.

As mentioned, we sought to develop an instrument that could predict several general psychological phenomena, especially clinical phenomena, through the parsimonious measurement of clusters of negative core beliefs. In this sense, this instrument may be able to measure categories of negative core beliefs common to several types of psychopathologies. Such commonality can highlight the categories of beliefs that are at the root of each clinical phenomenon. This capability, if confirmed, makes this instrument particularly useful for the transdiagnostic approach in psychological treatments, which is a recent and promising approach that seeks to understand and treat general aspects of psychological disorders.

\section{REFERENCES}

Abramson, L. Y., Seligman, M. E., \& Teasdale, J. D. (1978). Learned helplessness in humans: Critique and reformulation. Journal of Abnormal Psychology, 87(1), 49-74. http://dx.doi.org/10.1037/0021-843X.87. 1.49

Ainsworth, M. D. S., Blehar, M. C., Waters, E., \& Wall, S. (1978). Patterns of attachment: A psychological study of the strange situation. Hillsdale, NJ: Erlbaum.

Alloy, L. B., Abramson, L. Y., Walshaw, P. D., Cogswell, A., Grandin, L. D., Hughes, M. E., . . Hogan, M. E. (2008). Behavioral approach system and behavioral inhibition system sensitivities and bipolar spectrum disorders: Prospective prediction of bipolar mood episodes. Bipolar Disorders, 10(2), 310-322. http://dx.doi.org/10.1111/j.1399-5618.2007.00547.x

Bartlett, M. S. (1973). Tests of significance in factor analysis. British Journal of Psychology, 3, 77-85.

Beck, A. T. (1964). Thinking and depression: II. Theory and therapy. Archives of General Psychiatry, 10, $561-571$.

Beck, J. S. (2005). Cognitive therapy for challenging problems: What do do when the basics don't work. New York, NY: Guilford Press.

Beck, J. S. (2011). Cognitive behavior therapy: Basics and beyond (2nd ed.). New York, NY: Guilford Press.

Beck, A. T., \& Alford, B. A. (2011). Depressão: Causas e tratamento. São Paulo: Artmed.

Beck, A. T., Freeman, A., \& Davis, D. (2015). Cognitive therapy of personality disorders (3rd ed.). New York: Guilford.

Beck, A. T., Rush, A., Shaw, B., \& Emery, G. D. (1979). Cognitive therapy of depression. New York, NY: Guildford Press.

Botega, N. J., Bio, M. R., Zomignani, M. A., Garcia, C., \& Pereira, W. A. (1995). Transtornos do humor em enfermaria de clínica médica e validação de escala de medida (HAD) de ansiedade e depressão. Rev Saúde Pública, 29, 355-363.

Bowlby, J. (1973). Attachment and loss (Vol. 2). New York, NY: Basic Books.

Brennan, K. A., Clark, C. L., \& Shaver, P. R. (1998). Self-report measurement of adult romantic attachment: An integrative overview. In J. A. Simpson \& W. S. Rholes (Eds.), Attachment theory and close relationships (pp. 46-76). New York, NY: Guilford Press. 
Browne, K. (2005). Snowball sampling: using social networks to research non $\square$ heterosexual women. International Journal of Social Research Methodology, 8(1), 47-60. http://dx.doi.org/10.1080/ 1364557032000081663

Cazassa, M. J., \& Oliveira, M.S. (2012). Validação brasileira do questionário de esquemas de Young: Forma breve. Estudos de Psicologia, 29(1), 23-31. http://dx.doi.org/10.1590/S0103-166X2012000100003

Chen, F., Curran, P. J., Bollen, K. A., Kirby, J., \& Paxton, P. (2008). An empirical evaluation of the use of fixed cutoff points in RMSEA test statistic in structural equation models. Sociological Methods \& Research, 36(4), 462-494. http://dx.doi.org/10.1177/0049124108314720

Clark, D. A., \& Beck, A. T. (1999). Scientific foundations of cognitive theory and therapy of depression. New York, NY: Wiley.

Clark, D. A., \& Beck, A. T. (2011). Cognitive therapy of anxiety disorders: Science and practice: Guilford Press.

Wenzel, A. (2012). Modification of core beliefs in cognitive therapy. In I. R. de Oliveira \& I. R. de Oliveira (Eds.), Cognitive behavioral therapy (pp. 17-34). Rijeka, Croatia: Intech.

DeMars, C. (2010). Item response theory: Understanding statistics measurement. New York, NY: Oxford University Press.

Dobson, K. S., \& Dozois, D. J. A. (2010). Historical and philosophical bases of the cognitive behavioral therapies. In K. S. Dobson, K. S. Dobson, K. S. Dobson, \& K. S. Dobson (Eds.), Handbook of cognitive behavioral therapies (3rd ed. pp. 3-38). New York, NY: Guilford Press.

Dykman, B. M. (1998). Integrating cognitive and motivational factors in depression: Initial tests of a goalorientation approach. Journal of Personality and Social Psychology, 74(1), 139-158. http://dx.doi.org/10. 1037/0022-3514.74.1.139

Dziuban, C. D., \& Shirkey, E. C. (1974). When is a correlation matrix appropriate for factor analysis? Some decision rules. Psychological Bulletin, 81(6), 358-361. http://dx.doi.org/10.1037/h0036316

Flett, G. L., Besser, A., \& Hewitt, P. L. (2014). Perfectionism and interpersonal orientations in depression: An analysis of validation seeking and rejection sensitivity in a community sample of young adults. Psychiatry: Interpersonal and Biological Processes, 77(1), 67-85. http://dx.doi.org/10.1521/psyc.2014.77. 1.67

Fraley, R. C., Davis, K. E., \& Shaver, P. R. (1998). Dismissing-avoidance and the defensive organization of emotion, cognition, and behavior. In J. A. Simpson \& W. S. Rholes (Eds.), Attachment theory and close relationships (pp. 249-279). New York: Guilford Press.

Fraley, R. C., \& Shaver, P. R. (2000). Adult romantic attachment: Theoretical developments, emerging controversies, and unanswered questions. Review of General Psychology, 4(2), 132-154. http://dx.doi.org/ 10.1037/1089-2680.4.2.132

Hazan, C., \& Shaver, P. (1987). Romantic love conceptualized as an attachment process. Journal of Personality and Social Psychology, 52(3), 511-524. http://dx.doi.org/10.1037/0022-3514.52.3.511

Hollon, S. D., \& Kendall, P. C. (1980). Cognitive self-statements in depression: Development of an automatic thoughts questionnaire. Cognitive Therapy and Research, 4(4), 383-395. http://dx.doi.org/10.1007/ BF01178214

Young, J. (2003). Terapia cognitiva para transtornos de personalidade: Uma abordagem focada em esquemas. Porto Alegre, Brazil: Artmed.

Main, M. (1999). Attachment theory: Eighteen points with suggestions for future studies. In J. Cassidy \& P. R. Shaver (Eds.), Handbook of attachment: Theory, research and clinical applications (p. 845). New York, NY: Guilford Press.

McCrae, R. R., Kurtz, J. E., Yamagata, S., \& Terracciano, A. (2011). Internal consistency, retest reliability, and their implications for personality scale validity. Personality and Social Psychology Review, 15(1), 28-50. http://dx.doi.org/10.1177/1088868310366253

Mikulincer, M., Shaver, P. R., Gillath, O., \& Nitzberg, R. A. (2005). Attachment, caregiving, and altruism: Boosting attachment security increases compassion and helping. Journal of Personality and Social Psychology, 89(5), 817-839. http://dx.doi.org/10.1037/0022-3514.89.5.817 
Miller, L., Lovler, R., \& MacIntire, S. (2013). Foundations of psychological testing: A practical approach (4th ed). Thousand Oaks, CA: Sage Publications.

Morley, T. E., \& Moran, G. (2011). The origins of cognitive vulnerability in early childhood: Mechanisms linking early attachment to later depression. Clinical Psychology Review, 312(7), 1071-1082. http://dx. doi.org/10.1016/j.cpr.2011.06.006

Muraki, E. (1992). A generalized partial credit model: Application of an EM algorithm. Applied Psychological Measurement, 16(2), 159-176. http://dx.doi.org/10.1177/014662169201600206

Natividade, J. C., \& Shiramizu, V. K. M. (2015). Uma medida de apego: Versão brasileira da Experiences in Close Relationship Scale-Reduzida (ECR-R-Brasil). Psicologia USP, 26(3), 484-494. http://dx.doi.org/ 10.1590/0103-656420140086

Pietromonaco, P. R., \& Feldman Barrett, L. (2000). Internal working models: What do we know about knowing about the self in relation to others? Review of General Psychology, 4(no 2), 155-175.

Platts, H., Mason, O., \& Tyson, M. (2005). Early maladaptive schemas and adult attachment in a UK clinical population. Psychology and Psychotherapy: Theory, Research and Practice, 78(Pt 4), 549-564. http://dx. doi.org/10.1348/147608305X41371

Platts, H., Tyson, M., \& Mason, O. (2002). Early attachment and adult psychopathology: A review. Clinical Psychology and Psychotherapy, 9, 330-348.

Revelle, W. (2015). Psych: Procedures for personality and psychological research. Evanston, Illinois, USA: Northwestern University.

Rizopoulos, D. (2006). Ltm: An R package for latent variable modeling and item response theory analyses. Journal of Statistical Software, 17(5), 1-25. http://dx.doi.org/10.18637/jss.v017.i05

Rosseel, Y. (2012). Lavaan: An R package for structural equation modeling. Journal of Statistical Software, 48(2), 1-36. http://dx.doi.org/10.18637/jss.v048.i02

Rusk, N., \& Rothbaum, F. (2010). From stress to learning: Attachment theory meets achievement goal theory. Review of General Psychology, 14, 31-43.

Samejima, F. (1969). Estimation of latent ability using a response pattern of graded scores. Psychometrika, 34(S1), 1-97. http://dx.doi.org/10.1007/BF03372160

Smith, E. V. (2002). Detecting and evaluating the impact of multidimensionality using item fit statistics and principal component analysis of residuals. Journal of Applied Measurement, 3(2), 205-223.

Weston, R., \& Gore, P. A. (2006). A brief gguide to structural equation modeling. The Counseling Psychologist, 34(5), 719-751. http://dx.doi.org/10.1177/0011000006286345

Zigmond, A. S., \& Snaith, R. P. (1983). The hospital anxiety and depression scale. Acta Psychiatrica Scandinavica, 67(6), 361-370. http://dx.doi.org/10.1111/j.1600-0447.1983.tb09716.x

Acknowledgements AcknowledgmentsThis study was funded by the Fundação de Amparo à Pesquisa do Estado da Bahia (grant number BOL0584/2015). All procedures performed in studies involving human participants were in accordance with the ethical standards of the institutional and/or national research committee and with the 1964 Helsinki declaration and its later amendments or comparable ethical standards.

Correspondence regarding this article should be directed to Flavio Osmo, Universidade Federal da Bahia. E-mail: proflavio@gmail.com 